\title{
AS CIÊNCIAS SOCIAIS DA RELIGIÃO NO BRASIL
}

\author{
Pierre Sanchis ${ }^{1}$
}

Resumo: Apresenta-se aqui um panorama das sucessivas significações adquiridas pelas Ciências Sociais da religião no decorrer de sua recente institucionalização no Brasil. Sete "momentos" são destacados, com respectivas densidades de atenção temática. Surge primeiro, do interior mesmo das instituições religiosas, uma "sociologia religiosa", que se transformará pouco a pouco, autonomizando-se, em "Ciências Sociais da Religião". Vieram então as descobertas sucessivas da religião popular, da pregnância política da religião numa sociedade politicamente instável como a do Brasil, do persistente sentido religioso da religião, com as perguntas, decorrentes da secularização e do advento dos Novos Movimentos Religiosos. Correlativamente, chamaram - e chamam - a atenção os sinais de resistência das instituições. $O$ estudo conclui-se em direção a uma prospectiva: o "momento" de amanhã poderá ser marcado, de um lado, pelas novas modalidades da adesão dos indivíduos religiosos a suas instituições de referência, de outro lado pelos cruzamentos de um duplo pluralismo que implicará tanto religiões quanto culturas na problemática das identificações.

Palavras-chave: Ciências Sociais da Religião, instituições religiosas, individualização, secularização, pluralismo.

Abstract: This is a panorama of the successive meanings acquired by the Social Sciences of Religion during their recent institutionalization in Brazil. Seven "moments" are emphasized, each with their own respective density of thematic attention. The first of these moments comes from within religious institutions, a "religious sociology", that is gradually transformed and made autonomous, becoming "Social Science of Religion". Afterwards, successive discoveries of popular religion were made, being a politically impregnated religion in a politically unstable society such as Brazil, with a persistent religious sense of religion, and whose questions sprang from secularization and the advent of the New Religious Movements. Correlatively, what then called and still continues

${ }^{1}$ Professor Emérito da UniversidadeF ederal de Minas Gerais - Brasil.

Debates do NER, Porto Alegre, ANo 8, N. 11, P. 7-20, JAn./Jun. 2007 
calling attention are the signs of resistance from the part of traditional institutions. The study is concluded by pointing towards a prospective: tomorrow's "moment" may be marked, on the one hand, by the new modalities of religious individuals adhering to their own institutions of reference and, on the other hand, by crossovers between a double pluralism that implies religion as well as culture in the problematic of creating identities.

Keywords: Social Science of Religion, religious institutions, individualization, secularization, pluralism.

Não se trata aqui de uma história das Ciências Sociais da Religião no Brasil, nem da indicação de um itinerário bibliográfico, mas de uma simples retrospectiva, muito subjetiva, quem sabe superficial e, sem dúvida, incompleta. Ela pretende simplesmente encontrar um sentido - um dos sentidos possíveis - para uma trajetória que, por outro lado, não almejo desenhar de modo equilibrado: insistirei, talvez demais, sobre momentos que as novas gerações menos conhecem. Uma trajetória,enfim, que não pretendo que seja exclusiva do Brasil. Simplesmente, ela pode encontrar, em certos momentos, no Brasil, umas ressonâncias específicas. Por dois motivos: Ciências Sociais da Religião não é independente de Ciências Sociais tout court, e "religião", realidade social, não é independente da totalidade social onde se realiza. Em cada caso uma sociedade específica, onde o enfoque da Ciência Social será relativamente próprio. Mas o contrário é também verdadeiro: a trajetória das Ciências Sociais da Religião no Brasil foi também acompanhando sua trajetória internacional. E é por esta dimensão que começaria.

Falarei, então, em "primeira etapa"? Ou primeiro "momento", pois não se trata de etapas perfeitamente sucessivas, mas de momentos em parte sobrepostos uns aos outros, caracterizados por densidades diferentes das mesmas atenções temáticas. Neste sentido, até o "primeiro momento" teve seus precursores no Brasil. A Antropologia já tinha trabalhado com segmentos religiosos, considerados como "marginais" ("diferentes", exóticos, pitorescos ou problemáticos). Tanto com religiões indígenas (muito pouco), quanto (e muito mais) com as religiões afro que, primeiro consideradas como à parte da sociedade, como uns "nichos" - ou até uns quistos - nela, dignas 
de atenção segmentária, eram cada vez mais descobertas como parte significativa e ativa da cultura nacional... Ao contrário o catolicismo, central na sociedade brasileira, era por isso mesmo objeto de obras significativas de globalidade, mas apologéticas, que visavam frisar o seu laço genético com o Brasil (a começar pelas famosas Conferências Anchietanas, de 1897). Mas existiam já perspectivas analiticamenteprecursoras. Para citar só três: quanto ao catolicismo, a problematização genial de Gilberto Freire. "Catolicismo brasileiro"? Sim, mas: mais católico, ou mais brasileiro?Quanto ao candomblé, ou ao conjunto das religiões mediúnicas, entre outras as obras de Bastide, por um lado, de Cândido Procópio Camargo, por outro, as tratavam como parte efetivas e ativas do conjunto de transformações, antigas e contemporâneas, deste mesmo Brasil.

Mas comecemos pelo primeiro "Momento" do surto quase que institucional das Ciências Sociais da Religião no Brasil. Paradoxalmente, tomou forma primeiro no interior das próprias instituições religiosas:uma "sociologia religiosa”, como era chamada. Isso corresponde a uma corrente internacional: a descoberta pelas próprias religiões da Ciência Social Empírica como instrumento de melhoria da sua abordagem pastoral: conhecer a realidade para agir sobre ela, já que "religião" tendia a não mais ser vivida como um fenômeno "natural" ("naturalmente social")... Um olhar vindo de dentro, mas crítico. Grandes pesquisas das próprias instituições, na França, também na Bélgica, entre outros países, com envolvimento massivo do clero. Como um efetivo trabalho pastoral (pastoral-crítico - e, aliás, muito criticado pelas alas conservadoras), seguidode aplicações concretas: por exemplo,as Missõesdiocesanas, doravante estrategicamente orientadas a partirde um mapa da realidade social. Esta etapa foi importante no surgimento contemporâneo das Ciências Sociais Empíricas da Religião, por dois motivos. Por um lado, representou o início de um amoldamento sistemático (e oficial) das religiões à diversidade do mapa social: a cada grupo social sua modalidade religiosa. Por outro lado, constituiu-se então um primeiro cruzamento de olhares diferentes (pastoral e científico, empíricoe normativo) sobre uma idênticarealidade. Isso durante os anos de guerra e de imediato pós-guerra. Nesta empresa, os instrumentos científicos seriam: por um lado, a noção de "meio social” (meio agrícola, 
operário, classe média, industrial, etc.), noção que ia buscar sua inspiração mais em Le Play do que no marxismo; por outro lado, uma metodologia predominantemente sociográfica: descrição quantificada, levantamento de comportamentos ("práticas", isto é: "a prática", medir a prática ritual para aferir a qualidade da vida religiosa), projeções - abertas a intervenções institucionais e estratégias pastorais. O resultado era um recorte do "catolicismo" em camadasdiferenciadas, tanto do ponto de vista social ("catolicismopo pular") quanto do ponto de vista do envolvimento do fiel na sua vivência (católicos praticantes, católicos nominais, católicos "sazonais" - um tipo de religião natural,das estaçõesda naturezae dasestaçõesda vida, revestidode catolicismo). Visão nova, interna e utilitária, mas cheia de descobertas (por exemplo, a deste fundo antropológico da relação "sazonal" com o sagrado, mais radical, sólido e durável, que as suas formas confessi onais de "prática católica”).

Os mesmos promotores deste gênero de pesquisa implantaram-na na América Latina. O Pe. Houtard (peça-mestre dos Institutos de Pesquisa Sócio-religiosa da Universidade Católica de Louvain, e que mais tarde será assessor do governo Sandinista, na Nicarágua) empreende uma pesquisa internacional (com a participação, no Brasil,do Departamento de Estatísticas da Conferência dos Religiosos do Brasil - CRB) sobre as transformações sociais e religiosas na América Latina (1958-1963). Um livro-conclusão virá marcar as novas perspectivas: Elementos para uma sociologia do catolicismo latino-americano, do Pe. Emile Pin. Não fala explicitamente em "religião popular", ou "catolicismo popular", mas aponta para este vasto continente sócio-religioso que a(s) instituição(ções) parecia(m) ignorar.

Inspirada por ele e na esteira deste movimento, aqui no Brasil, a CNBB monta, no bojo de sua crise pós-conciliar, e no início do governo autoritário, um programa de pesquisas - históricas e sociológicas - sobre a realidade religiosa, especialmente popular. As perspectivas já são críticas e reformistas: reconquista para um catolicismo "autêntico" do espaço do catolicismo popular. Mas este "autêntico" pós-conciliar, não seria mais o conservador tradicionalista.

Pois uma chave dia-crítica emergia então para distinguir duas vertentes do "popular" (o popular "autêntico", aceitável pela pastoral moderna porque

Debates do NER, Porto Alegre, ANo 8, N. 11, P. 7-20, JAN./Jun. 2007 
potencialmente conscientizador nas perspectivas cristãs, e o popular deformado, a ser transformado): o engajado e o alienado. Isso no horizonte de uma sociabilidade de desenvolvimento integral e convivência igualitária...

A partir dali, as duas perspectivas, pastoral e acadêmica, começam a se articular, através de relações pessoais, de pesquisas conjuntas, de assessorias. Por exemplo, o programa de pesquisas organizadas pela CNBB foi em parte realizadopela AssociaçãoLatino-Americanade Sociologia (sediadaem Santiago, mas com a sua biblioteca no Rio, dirigida pelo Prof. Manoel Diegues), em que trabalharam vários jovens sociólogos mais tarde conhecidos. E nascem organismos em que possam se juntar institucionalmente as duas vertentes. Do lado católico, fundado por um padre - hoje bispo - formado em Sociologia na Universidade de Louvain, o CERES, instituto de sociologia religiosa diretamente ligado à $\mathrm{CNBB}$. Do lado protestante, num primeiro nível, o Movimento Ecumênico se organiza, dotando-se de uma vertente sociológica (vários militantes ou pastores são sociólogos e fundam o que até hoje se tornará o movimento koinonia), num outro nível - e outro momento - uma reunião informal, pouco a pouco formalizada em termos de instituição, de pastores, teólogos e militantes intelectuais em dificuldades com suas denominações (momento da ditadura, e de seus efeitos em várias congregações protestantes), rapidamente tornada duplamente ecumênica: primeiro pela presença de católicos, também teólogos, sociólogos e pastoralistas, em seguida pela participaçãocresœnte deintelectuais, universitários (sociólogos, antropólogos, filós ofos, historiadores), não necessariamente religiosos mas, pess oalmente interessados pelo destino e a influência sociais da religião: esta "encruzilhada" da vivência religiosa e do olhar acadêmico sobre a religião se tornará o ISER (Instituto Superior de Estudos da Religião, mais tarde, sinal de sua natureza não formalmente acadêmica: Instituto de Estudos da Religião). Caixa de ressonância (uma das...) de uma reflexão que se espalhava nas universidades, em torno de um olhar possivelmente renovado sobre as relações entre razão e religião, ciência e religião (não se falava muito, como mais tarde, de Razão e Fé).

A partir dali, de fato, e no decorrer de um Segundo Momento, afirma-se um movimento de autonomização deste pensamento relativamente às matrizes religiosas denominacionais. 
Mais uma vez, numa analogia com a Europa. Para citar somente as correntes que influíram mais diretamente no Brasil, na França, por exemplo, pela iniciativa de vários intelectuais religiosos secularizados nasce o Groupe de Sociologie des Religions de 1'Ecole des Hautes Etudes em Sciences Sociales, com sua revista Archives de Sociologie des Religions - e não, como inicial mente entrevisto, "de sociologie religieuse" ou "de sociologie de la religion”. Evolução dos títulos, bem significativa de uma diversificação, um alargamento, uma neutralidade progressiva. Finalmente: Archives de Sciences Sociales des religions. O próprio Grupo se transforma rá no Centre d'Etudes Interdisciplinaires des Faits Religieux (CEIFR, CNRS/EHESS). Num outro ramo do CNRS (equivalente do CNPq...), Groupe de Sociologie des Religions et de la Laïcité. Com seu paralelo na EPHE (Section des sciences religieuses): Institut d'Études des Religions et de la Laïcité, cujo diretor foi por muito tempo titular de uma cátedra: Chaire d'Histoire et Sociologie de la Laïci té. Isso tudo numa universidade laica, sem influência eclesiástica institucionalizada.

Na Bélgica, é no seio de uma universidade católica, a de Louvain, que a mesma evolução vai se processar. A revista Social Compass, por exemplo, que tinha começado como uma publicação de sociografia do catolicismo, órgão de um instituto sócio-eclesiástico católico (ISKA), passará sob a regência da FERES(Fédération Intemationaledes Institutsde RecherchesSocialese Socioreligieuses), antes de adquirir o seu estatuto definitivo de revista científica, sob a égide do Centre de Recherches Socio-religieuses de 1'Université de Louvain e a chancela da Société Internationale de Sociologie des Religions (anteriormente: Conférence Internationale de Sociologie religieuse).

Um terceirocaso seria o da única universidade oficialfrancesa sob regime concordatário, em Strasbourg, onde existem estatutariamente programas explícitos de religião e faculdades de teologia. $\mathrm{O}$ tema, ali, não só sofre maior ampliação, tanto temática quanto geográfica (Europa), mas se insere mais organicamente no corpus acadêmico. Surge o PRISME (Politique, Religion, Institutions et Sociétés: Mutations Européennes), resultado da fusão sucessiva (e recente) de três unidades de pesquisa, todas sobre Sociedade, Direito, Europa, Política, Religião.

Debates do NER, Porto Alegre, ANo 8, N. 11, P. 7-20, JAn./Jun. 2007 
A Revista das Archives, doravante perfeitamenteacadêmica, acaba sendo de responsabilidade das três instituições francesas, situadas nos dois tipos de Universidade.

No Brasil, a novidade foi o projeto da Universidade de Brasília, de Darcy Ribeiro, que incluiria uma faculdade de teologia. Não se realizou. Mas a iniciativa levantou um problema: como articular, na Academia, um duplo estudo da religião, a partir de dentro (teologia) e, a partir de fora, com o instrumento objetivante da Ciência Social. Fé e Razão... Problema de vários rostos, e que continua atual, com o surto, nas universidades, de centros de estudos da religião, de visada em geral claramente objetivada, e, mais recentemente, de programas de pós-graduação em estudos da Religião que, de mil maneiras, procuram uma convivência ativa e epistemologicamente produtiva entre as duas perspectivas, incluindo a teológica. $\mathrm{O}$ que ocasiona ainda hoje um rico debate, inclusive do ponto de vista da administração acadêmica (CAPES).

Em todo o caso, vê-se que, nesta trajetória toda, trata-se do assunto "religião", sob forma singular ou plural, e de suas adjacências, eventualmente contraditórias: "religioso sem religião", "ateísmo”...

O grande problema, no desdobramento desta etapa (Terciro "Momento") e na encruzilhada destas duas vertentes, será precisamente - particularmente mas não só no Brasil - o da "religião popular". Objeto novo, para os de dentro, objeto "independente", para os de fora, que lhes permitia entrar no universo das religiões sem passar pelas ortodoxias e as instituições... Diálogo e controvérsias... O que seria, de fato, uma religião popular? Rapidamente, impõe-se a constatação de que religião popular não é simplesmente religião "outra", mas é inteiramente religião "relativa". Ela integra um "campo", no sentido de Bourdieu, opondo-se dinamicamente. A quê? Na totalidade do campo, pode ser a outras religiões (ou outra religião), dominante(s): existem religiõesinstitucionalmente populares neste sentido.Mas tambémno interior de uma denominação, correntes "populares" existem, que se opõem (ou se articulam com) à religião oficial da instituição. Duas vertentes de definição, às vezesdificilmenteconciliáveis:o popularreferido a classessociais populares, e o popular referido às relações de autoridade no interior das instituições.

Debates do NER, Porto Alegre, ANo 8, N. 11, P. 7-20, JAn./Jun. 2007 
De qualquer jeito: um popular definido como enfrentando (e enfrentado por), mesmo em meio a toda uma rede de simbioses, uma realidade social de elite. E assim, preso numa dialética. O "popular" é cada menos visto como compondo uma realidade "em si", muito menos uma realidade social au tônoma. Neste sentido é que, para alguns - até hoje - o problema da religião popularteria sido um falso problema. Mas ele é pólo de um embaterelacional, uma dialética que formata e reformata as realidades sociais em função das metamorfoses das relações sociais de autoridade. Uma religião popular não substantiva, mas relativa.

E por isso mesmo política. Será esta a dimensão em parte secretamente dominante nas $\mathrm{C}$ iências Sociais brasileiras do seguinte período (Quarto Momento). No cerne desta fermentação, descobre-se que o fator religioso tambémpode ser socialmente ativo,num sentidode resistência e de libertação. Falo em "descoberta", pois até então a dimensão religiosa tinha chamado pouco a atenção no meio acadêmico das Ciências Sociais. Uma tese recente ilustra o fato pelo caso de um grupo de estudantes de Ciências Sociais numa Universidade de BeloHorizonteindo fazerpesquisa no Vale do Jequitinhonha, e não atribu indomaior peso significativo ao profundo veioreligiosodas populações. Visão de mundo e motivações que lhes pareciam não ter impacto notável sobre a realidade da vida social. Cegueira quase que programada, poderia dizer a autora, porque estes cientistas sociais não possuíam no seu instrumental teórico uma grade capaz de outra apreensão. Mas a situação política brasileira (a ditadura) imporia logo a descoberta. Lembro de um psicanalista - ex-pastor e professor de filosofia - que me dizia em 1976, a propósito da Teologia da Libertação como corrente de religião popular: "Este governo descobriu que o 'pobre' da Teologia da Libertação é mais perigoso para ele do que o 'proletário' do marxismo".

$\mathrm{Na}$ verdade, tanto no esforço analítico interno às religiões - que os cientistas sociais observavam -, quanto nas realidades sociais populares que eles pesquisavam, estas duas dimensões do "povo" se articulavam efetivamente (dimensão analítica - de fato, marxista - e dimensão bíblica, costumava dizer-se) .

Durante anos, a Ciência Social das Religiões no Brasil concentrou-se assim nesta relação entre Religião e Política, a dominante deste quarto 
Momento. Ao longo do caminho vislumbravam-se outras perspectivas. Mas eram parênteses - eventualmente ricos - e a pergunta perdurava: em que medida a visão do mundo e a vivência religiosas, especialmente num caso como o do Brasil, onde elas são "de massa", podem contribuir para a criação disruptiva de nova sociedade, sociedade de equidade e liberdade, justiça e não-exploração?

As respostas eram as mais diversas, até no nível das comprovações empíricas. Lembro de um debate quente, na UFMG, por ocasião do lançamento de um número de Religião e Sociedade, a revista do ISER, que tinha por título "Marxismo e Religião". Mas o problema estava subjacente aos diálogos.Mais uma vez orquestrado em parte em referênciaa outros diálogos, internacionais desta vez, que mobilizavam autores paradoxais, criativos na ponte que ofereciam entre o tema da religião e a teoria marxista. Foi significativo,por exemplo,a intensidade com que se usou o pensamento de Gramsci (em certa ocasião os alunos indicaram como tema de um curso desejado por eles: "Gramsci e os movimentos messiânicos brasileiros", estes mesmos movimentos que, no plano nacional Douglas Teixeira Monteiro - outro precursor - acenava como fonte de um autêntico projeto político popular, em função mesmo do seu conteúdo religioso).

Quinto Momento: a democratização.Ocorreu-me esta palavra quase que automaticamente... Sem dúvida, ela não constitui um tema nas Ciências Sociais da Religião, mas sua irrupção no discurso comprova um paralelismo entre estado global da sociedade, vivência efetiva da religião e enfoques da Ciência Social sobre a mesma. A "democratização" liberou o fiel da exclusividade da relação entre "Religião" e "Política" (com bemóis de relativização diante de cada um destes termos), e impôs aos analistas sociais uma refocalização de suas lentes.

Surpresa para alguns cientistas sociais, mais especialmente aqueles seduzidos pelas perspectivas de uma eficácia sociopolítica "progressista" da religião. Assim,a religião importapara as pessoasem funçãode outrosinteresses,talvez, aliás, os mesmos (saúde, felicidade, subsistência e nível de vida, experiência de ultrapassamento do quotidiano concreto, etc.) mas numa dimensão individual e limitada a este mesmo quotidiano.Esta dimensão era antiga, já tinha 
dado lugar a pesquisas e livros importantes (sobre cura, por exemplo). Mas ela vira central, enraizada numa "experiência religiosa", que encontra nela própria sua justificativa, mesmo quando se institucionaliza no surgimento de uma multidão de grupos, de comunidades, de igrejas: os "Novos Movimentos Religiosos".

Mais uma lembrança: a daquele colegaestrangeiro, diante de quem numa reunião recente eu havia evocado a hipótese de uma restauração da Igreja Católica num sentido pietista tradicional, como no Século XIX, sendo que tinha descartado toda possibilidade disso no mundo atual, e que, de repente, no meio de uma viagem ao Brasil, me telefona: "Observei, conversei... Não o imaginávamos, mas está em toda parte...". Em toda parte do espaço "religioso", queria dizer: mundo pentecostal, mundo carismático. Tal invasão de campo bastavapara oferecernovo objeto às $C$ iênciasSociais da religião,mas também para impor-lhes um tipo de olhar novo. $\mathrm{O}$ fenômeno exigia um tipo de atençãoespecífica. Tantomais que,cada vezmais, eletransbondava,além de suas próprias fronteiras, sobre o espaço público, através - entre ou tros - dos meios massivos de comunicação.

Uma pergunta, pelo menos implícita, vai então dominar este Quinto Momento, aquela do que se convencionou chamar de "Secularização". Este surto de religião que parecia paradoxalmente acompanhar a modernidade, seria real ou ilusório? Fruto de uma onda estrutural ou de provisórios contingenciamentos conjunturais? Mais uma vez, afluíam as referências teóricas e analíticas internacionais, mas uma rica jazida nacional estava sendo oferecida à pesquisa empírica. Teoria e empiría se cruzavam, de maneira às vezes complexa e que suscitavatodo um jogo de interpretações. Qual era a natureza deste "sagrado" que, ao mesmo tempo que sendo expulso, dava a impressão de "voltar"? Para alguns, era a própria religião que a modernidade havia inexoravelmente começado a expulsar, do campo da determinação social e do campo da plausibilidade epistemológica. A aparência contrária era simples atraso. Para outros, ela perdeu somente o seu papel, fundamental é verdade, de raiz estruturante do mundo social - ou até mesmo das identidad es pessoais -, mas tinha conservado - podendo inclusive ampliá-la - sua presença na construção das experiênciassubjetivas,individuaise, até certoponto, coletivas.

Debates do NER, Porto Alegre, ANo 8, N. 11, P. 7-20, JAn./Jun. 2007 
Para outros, enfim, a repercussão da modernidade sobre o papel da religião nas trocas sociais estruturantes e estruturadas não se poderia generalizar. Haveriasociedades em processode secularização acelerada, mas outrasem que se instituía uma modernidade até certo ponto religiosa.

Secularização, em todo caso, era o tema instigante e o instrumento de explicação. Mas chegou-se afinal a certo consenso, pelo menos implícito. Não se deveria, talvez, indagar até que ponto desaparecia, ou permanecia, ou até voltava, o fenômeno religioso, mas em que termos a modernidade o transformava. Metamorfose incontestada, ela.

Mais um Momento (o Sexto), de interesse, de estudo, de fascínio, depois do embate da modernidade, para e pelas formas novas, "pós-modernas " da religião. Estaremos ainda vivendo este Momento? Não de novidade absoluta, está claro - pois isso neste campo nunca existiu. Mas novidade e metamorfose serão os lemas deste Momento. Não detalharei, pois o tema está presente na memória de todos os leitores desta literatura. Emergência definitiva do indivíduo, critério mais de experiência do que de verdade, recusa da fixação e da definição. Andança peregrinae Procura. Por isso tudo, perda de influência das instâncias definidoras:desinstitucionalização,trânsito, relativizaçãoe fluidez das identidades. Como dos conceitos. Cultivo de um universal simbolismo. Hibridismo.

Um "estado das mentes" portado por uma onda que, não podendo ser dito "movimento", é fluxo polimorfo e polivalente de modo de pensar e de ser, suficientemente denso e autonomamente assumido para ser objeto de auto e hetero-reconhecimento: a Nova Era; mas também suficientemente difusivo, comunicativoe dialogal para atingir,penetrar, colorir e até reformatar identidades coletivas institucionalizadas. Marca universalizável, parecia aos cientistas sociais.

Ao mesmo tempo, no entanto, ou como conseqüência reativa desta agudeza de percepção, freqüentemente nos mesmos autores, emerge outro Momento lógico (o Sétimo), aquele que vai estar sensível à resistência das instituições. Apesar da fluidez em contrário, identidades se afirmam vistosamente, às vezes umas contra outras. Toda uma literatura descobre realidadesde revivescênciasem religiõestradicionais, às vezescomo duastradições 
(identidades) articuladas (o toré com a missa), estruturas novas se afirmando em toda parte ou então, no seio das próprias estruturas antigas, movimentos introduzindonelas um dinamismoque, começandono segmento(dos jovens por exemplo), acaba levando o todo a uma visibilidade social significativa, recuperando aspectos tradicionais (aumento do número de seminaristas) e revestindo-os de uma expressividade moderna (carismáticos); ou ainda fermentações pontuais (aparições marianas) que cristalizam pouco a pouco em coletivosinstitucionalmenteregulados;nas margens dasinstituições, gr upos aparentemente heteróclitos, em grande parte espontâneos, e que acabam entrando na esfera das igrejas, legitimados porque canalizados mais ou menos explícita e consentaneamente. Enfim - acontecimentos recorrentes, como a viagem do Papa, a Marcha paraJesus, queocupam os meiosde comunicação e mobilizam as massas, serviriam, entre outros, de exemplo - não faltam afirmações institucionais de vigor e tamanho nunca alcançado... Nem o nível das estatísticas fica fora da onda: institutos de pesquisa de opinião obtiveram recentemente resultados que poderiam assinalar um momento de pausa (?) - de parada (?) ou de ritmo mais lento (?) - no recuo sempre comentado da instituição ontem hegemônica. Resistência das instituições.

E com isso, estamos no hoje. Provavelmente não seja inútil aqui frisar de novo que o que chamamos de Momentos não são períodos adequadamente sucessivos. Momentos essencialmente lógicos, embora se sucedam insistênciascontrastadas na literatura.

Para terminar,me será permitido evocar agora uma prospectiva, ulterior Momento para as Ciências Sociais da Religião no Brasil? Falamos das instituições, de sua perda de centralidade e de sua correlativa resistência. Mas de que tipo de instituição doravante se tratará? As mesmas que definham serão as que se reafirmam? E de que serão feitas as relações que manterão com elas os fiéis que nelas buscarão a referência de sua identidade?

Se pudesse imaginar para o Momento de amanhão tipo de sensibilidade temática que irá marcar as ciências sociais da religião no Brasil, indicaria dois pontos:

O primeiro,é a indagaçãosobre o novo modelo de arranjo que o indivíduo religioso, definitivamente afirmado, saberá encontrar para suas relações com sua

Debates do NER, Porto Alegre, ANo 8, N. 11, P. 7-20, JAn./Jun. 2007 
instituição. Sem dúvida, a afirmação institucional de ontem, definidora e criadora de identidades totais, não se reproduzirá simplesmente. Os laços de adesão, de conformidade, dogmática e ética, de expressão ritual provavelmente sofrerão um processo de diversificação relativizadora.

E o segundo ponto decorreria de uma teimosa pluralização. "Relações com sua instituição", dizia. Mas cada vez mais esta instituição não é única a lhe dizer respeito. Consciente ou inconscientemente. Sob as categorias da religião ou sob as formas da cultura. Quantas encruzilhadas marcam hoje as múltiplas passagens entre estes dois níveis da construção interior, Religião e Cultura? A pluralidade religiosa (o pluralismo religioso, na verdade), acaba constituindo, não só um "campo religioso" conflitual mas também um "campo cultural" tendencialmente consensual, ou pelo menos em que o consenso constitui o problema. Nele se encontram as religiões, e a influência de cada uma delas é mais larga do que o raio das adesões religiosas aos seus dogmas e ritos. O seu imaginário, cosmológico, ritual, mítico, ético, perpassa o quotidiano em amplas camadas da população: muitas vezes não se sabe onde começa a religião e onde acaba a cultura. E a vivência cultural brasileira é feita - e será cada vez mais feita - destes encontros e destas transmutações: o que é, nela, cultura católica, cultura espírita, cultura afro? Como nela convivem, se estranham e se articulam catolicismo-religião com culturas afro e espírita, espiritismo com cultura católica e cultura afro, candomblé com culturas espírita e católica?

Tal momento de atenção - se de fato ocorrer - poderá recapitular todos os outros,reativar suas potencialidades de indagação. Porum lado, as religiões que, muitas vezes, vimos tratados como universos separados, estarão aqui articuladas, dinâmica e misteriosamente. Pois várias delas existem dentro da cultura brasileira e se expressam - e se constituem - através dela. Dois exemplos: a da Mãe de Santo fervorosa adepta da corrente anti-sincretistano Candomblée admiradora da Mãe Estela,líder desta corrente,que me contava tranqüilamente do batizado dos seus netos. Diante da minha surpresa: "Ah! Mas isso é outra coisa. Não é religião. Faz parte de nossa cultura brasileira”. Ou, num sentidodiferente,a destejovem negro,militante católico e secretário de paróquia, que descobre de repente numa sessão de candomblé o "seu"

Debates do NER, Porto Alegre, ANo 8, N. 11, P. 7-20, JAn./Jun. 2007 
Deus, o "Deus de nosso jeito", Deus vivo que se celebra pela Vida - mas que não muda por isso de afiliação religiosa. Até onde se distinguiam ou identificavam o Deus da sua cultura, o Deus de sua Fé?

Poroutro lado,as ênfases de todos os momentos que levantamostambém estão aqui, com suas dominantes, seus lemes, seus vieses.Está aqui a injunção, para cada religião, de uma visão crítica de si mesmo a partir de dentro; está aqui uma volta à pedra de toque do "popular", sendo por exemplo necessário, para evitar projeções classistas nossas, identificar a possível existência de uma Nova Era popular; está aqui a política, com as reivindicações das instituições por sua visibilidade no espaço público, tanto cultural quanto político; está aqui a secularização, desta vez pela presença explicitada da cultura contemporânea secularizada, no bojo da qual as instituições religiosas e as vivências individuais dos fiéis são instadas a decidir-se pela inculturação ou a contraaculturação... - ritual, noética e ética. Inclusive em estado de mútuo afastamento ("religiosos sem religião", isto é, sem instituição religiosa). E assim dos suces sivos temas, retomados em nova chave a partir do enfoque: Pluralismo cruzado de cultura e religião, de culturas e religiões...

Termino, pois, simplesmente sugerindo que as Ciências Sociais da Religião no Brasil não parecem ter acabado de descobrir e propor achegas enriquecedoras ao fenômeno que elas estudam.

Falei do próximo futuro com as expressões : "Sem dúvida", "está chegando..." "irá marcar...". Talvez devesse dizer mais timidamente: "provavelmente", "Quem sabe...". Pois neste campo também, e apesar das teorias dos cientistas sociais, brasi leiramente "o Futuro a Deus pertence".

Recebido em 13/06/2007.

Debates do NER, Porto Alegre, ANo 8, N. 11, P. 7-20, JAn./Jun. 2007 